Reseña

\section{Isabel Bartolomé Rodríguez, Mercedes Fernández-Paradas y Jesús Mirás Araujo (eds.). Cercanas pero distintas. La desigual trayectoria de la industria del gas en las regiones del sur de Europa (siglos XIX-XX). Madrid, Marcial Pons, 2020, 365 pp. ISBN: 978-8491238508.}

Este libro y su inmediato predecesor de los mismos editores académicos (Globalización, nacionalización y liberalización de la industria del gas en la Europa latina, siglos XIX-XX. Madrid, Marcial Pons, 2017) constituyen un todo que responde a una nueva estrategia en lo que hace a los estudios sobre la industria gasista, una estrategia de la que también forma parte un número monográfico de la Revista de Historia Industrial (n. 71, 2018). Con anterioridad habían predominado los estudios monográficos sobre empresas específicas y sobre el desarrollo tecnológico de la industria en España. Financiados y publicados en su mayor parte por la Fundación Naturgy (antes Gas Natural-Fenosa y antes aún Gas Natural), estos trabajos ofrecen hoy en su conjunto una visión casi completa del surgimiento y expansión de la industria; eso sí, atendiendo básicamente a los aspectos empresariales y tecnológicos y con menor atención a las grandes fases energéticas o a las condiciones que se daban en España para el desarrollo global del sector.

La nueva perspectiva implica una ampliación y diversificación del ámbito temático, incorporando una mayor voluntad analítica y comparativa. Por ello, las tres colecciones de artículos mencionadas incorporan también autores extranjeros, cuyos trabajos aportan elementos de comparación y facilitan la elaboración y el debate de hipótesis de rango supranacional.

El monográfico cuenta con dieciséis trabajos divididos en tres partes de carácter territorial. La primera presenta cinco trabajos referidos a países extranjeros o de carácter comparativo internacional; la segunda, agrupa otros seis, centrados estos en Cataluña, mientras que los cinco restantes conforman la tercera parte, referida a las otras regiones españolas.

La primera parte incluye aportaciones de dos de los más reconocidos especialistas en la historia industrial del gas a nivel europeo, Jean-Pierre Williot y Andrea Giuntini. Ambos abordan temas de interés referidos a sus respectivos países. Williot estudia el proceso de concentración regional de las empresas gasistas francesas antes de la nacionalización. Giuntini, por su lado, analiza el impacto que tuvo sobre la economía y la sociedad italianas el descubrimiento de gas natural en la Lombardía, primero, y en la Emilia Romagna, después.

La participación de los municipios en el desarrollo de la industria del gas es justamente el eje del trabajo comparativo de Alexandre Fernández y Carlos Larrinaga sobre las ciudades de San Sebastián, Bilbao y Burdeos. El recorrido por las vicisitudes de cada caso ayuda a comprender el papel de los diversos factores en presencia, pero abre otras incógnitas tanto o más relevantes.

Ana Cardoso de Matos, Mercedes Fernández-Paradas y Nuria Rodríguez han escogido un periodo especialmente crítico - los años de la Primera Guerra Mundial- y dos ciudades comparables: Lisboa y Madrid para realizar ese ejercicio en lo referido al suministro de gas. Las dificultades de acceso a la principal materia prima, el carbón mineral, y el consiguiente aumento de su precio situó a las compañías que alumbraban ambas ciudades ante la imposibilidad de mantener la regularidad y la calidad del servicio.

Diego Bussola aplica el método comparativo al estudio de las industrias del gas de Cádiz y Buenos Aires de la segunda mitad del siglo xIx. Pienso que en este caso la comparación aporta poco tanto al análisis general como al de cada caso. Este lector hubiera preferido que el espacio dedicado al lejano espejo gaditano se hubiera dedicado a ampliar el interesante resumen que se nos ofrece sobre el desarrollo de la industria del gas bonaerense.

La segunda parte del libro agrupa trabajos referidos a Cataluña. La opción territorial parece razonable en esta ocasión dado el carácter pionero que tuvo la industria del gas en Cataluña desde el mismo momento de su aparición y también por la existencia de un mayor número de trabajos dedicados a su estudio. Esto último queda plenamente evidenciado en el ensayo bibliográfico realizado por Jorge Ranea, donde se contabilizan hasta 43 referencias. Pere Fábregas, decano y gran impulsor de la historia gasista española, aborda un tema de la mayor importancia y prácticamente virgen: el estudio social y económico de los primeros consumidores de gas.

Anna Aubanell nos presenta una visión de conjunto del entramado de capitalistas, emprendedores y técnicos que impulsó el desarrollo de la industria del gas en Cataluña: españoles y extranjeros, experimentados y neófitos, con capital propio o sin él, la tipología es diversa, pero permite ya acercarse a la dinámica empresarial del periodo para el espacio catalán. A este panorama será necesario incorporar las aportaciones de Alayo y Barca sobre las fábricas de José Piñol y Cía. y, eventualmente, también la de Jesús Sánchez Miñana y Carlos Sánchez Ruiz sobre la empresa Ciervo, pionera en la producción de contadores en España.

Un carácter completamente distinto tiene el capítulo dedicado por Mariano Castro y Juan Manuel Matés a las transformaciones experimentadas por Catalana de Gas durante la década de 1960-1969. Se trata de un periodo decisivo para el sector gasista español en el que se fraguó la llegada del gas natural a España de la mano de Catalana y se produjo la brutal apropiación por el Estado de todos los activos y contratos firmados en relación con el nuevo combustible. 
La última parte del libro objeto de esta reseña lleva como título "El gas en otras regiones españolas». Responden efectivamente a ese encabezamiento dos de los cinco trabajos que la integran: los dedicados al desarrollo de la industria gasista en Castilla y León (por Pedro Amigo) y a la comparación entre Andalucía y Galicia en lo referido al consumo de gas (por Fernández Paradas, Martínez y Mirás). Me parece, sin embargo, que este tipo de ejercicios serían más instructivos si se orientasen, por ejemplo a analizar por qué dos ciudades portuarias con precios del carbón y densidad demográfica similares tuvieron distintas trayectorias gasistas.

El análisis jurídico de pleito derivado de la incautación por parte del Ayuntamiento de Madrid de la fábrica de gas, que nos presentan Nuria Magaldi y Nuria Rodríguez Martín, ayuda a comprender por qué el sistema jurídico español representaba una grave dificultad para el desarrollo de las actividades económicas. La resolución judicial de cualquier conflicto era extremadamente lenta y conllevaba elevados costes en minutas y trámites.

La investigación desarrollada por Mercedes Fernández-Paradas y de Antonio-Jesús Pinto Tortosa abordan la relación de Willian Partington, figura clave de la industria del gas, con
España. Sus pesquisas en el Archivo Militar de Segovia han permitido fijar los hitos más relevantes de su vida en España.

Por último, el trabajo de Antonio Rafael Fernández Paradas estudia el gas como elemento configurador del espacio festivo en las ciudades. Se centra en los fastos que tuvieron lugar en Madrid con ocasión del final de la tercera guerra carlista, la Restauración de la monarquía y la entrada del rey Alfonso XII en la capital el 20 de marzo de 1876.

Como indicábamos al principio, este nuevo libro editado por Bartolomé, Fernández-Paradas y Mirás amplía y profundiza en diversos aspectos nuestro conocimiento sobre el sector gasista español, añadiéndose así a otras publicaciones colectivas recientes. El volumen de trabajos hoy disponibles hace pensar que quizá haya llegado el momento de emprender la elaboración de una síntesis que dé debida cuenta de la trayectoria del sector y permita integrarlo en el marco general de la transformación energética de la España contemporánea.

Carles Sudrià Universitat de Barcelona

https://doi.org/10.33231/j.ihe.2022.01.003 